\title{
Ecology of Caenorhabditis species ${ }^{*}$
}

Karin Kiontke ${ }^{\S}$, Department of Biology, New York University, New York, NY 10003 USA

\section{Walter Sudhaus ${ }^{\S}$, Institut für Biologie/Zoologie, Freie Universität Berlin, D-14195 Berlin, Germany}

\section{Table of Contents}

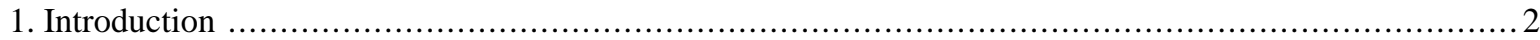

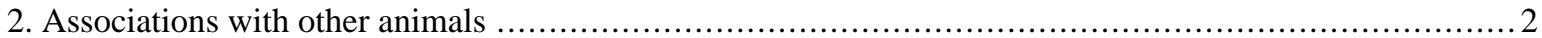

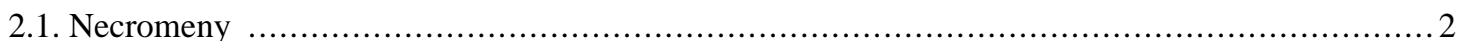

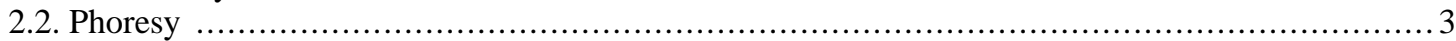

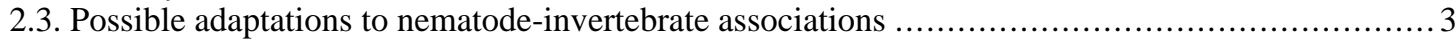

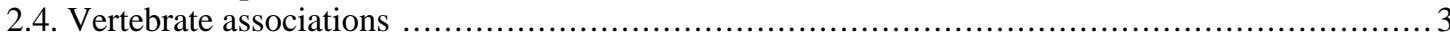

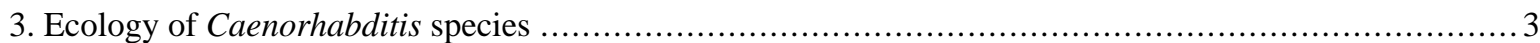

3.1. Ecology of $C$. briggsae, $C$. elegans and $C$. remanei ............................................... 4

4. Ecology of the Caenorhabditis stem species and evolution of ecological features within Caenorhabditis .. 5

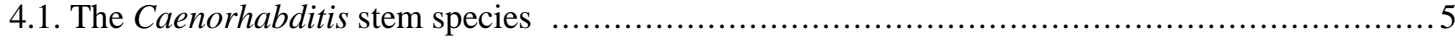

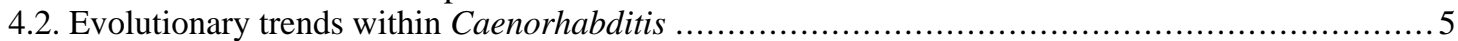

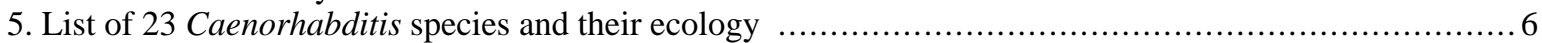

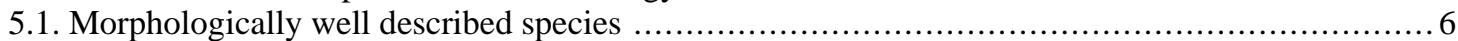

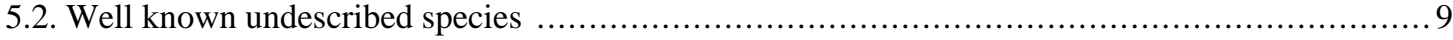

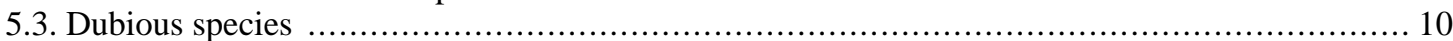

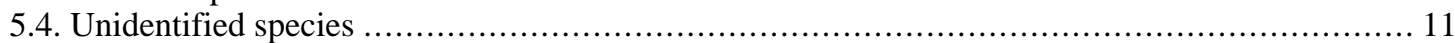

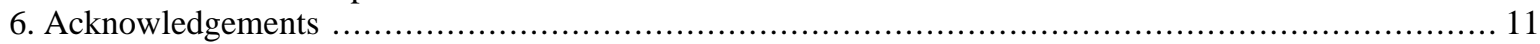

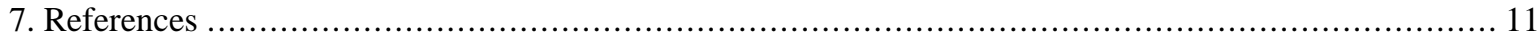

\begin{abstract}
Although several Caenorhabditis species are now studied in laboratories in great detail, the knowledge of the ecology of most Caenorhabditis species is scarce. In this chapter we present data on the habitat, animal associations, and geographical distribution of the eighteen described and five undescribed Caenorhabditis species currently known to science. The habitats of these species are very diverse, ranging from rotting cactus tissue to inflamed auditory canals of zebu cattle. Some species, including $C$. elegans, have only been isolated
\end{abstract}

\footnotetext{
*Edited by David H.A. Fitch. Last revised December 6, 2005. Published January 09, 2006. This chapter should be cited as: Kiontke, K. and Sudhaus, W. Ecology of Caenorhabditis species (January 09, 2006), WormBook, ed. The C. elegans Research Community, WormBook, doi/10.1895/wormbook.1.37.1, http://www.wormbook.org.

Copyright: (C) 2006 Karin Kiontke and Walter Sudhaus. This is an open-access article distributed under the terms of the Creative Commons Attribution License, which permits unrestricted use, distribution, and reproduction in any medium, provided the original author and source are credited.

${ }^{\S}$ To whom correspondence should be addressed. E-mail: kk52@nyu.edu or sudhaus@zedat.fu-berlin.de
} 
from anthropogenic habitats. Consequently, their natural habitat is unknown. All Caenorhabditis species are colonizers of nutrient- and bacteria-rich substrates and none of them is a true soil nematode. Dauer juveniles of many Caenorhabditis species were shown to be associated with terrestrial arthropods or gastropods. An association with invertebrates is also likely for the remaining species. The type of association is either phoresy (for transport to a new habitat) or necromeny (to secure the body of the associated animal as a future food source). There are also some records of Caenorhabditis species associated with vertebrates. The Caenorhabditis stem species was probably a colonizer of nutrient-rich substrates and was phoretic on arthropods. Some evolutionary trends within the taxon are discussed.

\section{Introduction}

The genus Caenorhabditis comprises morphologically quite similar but ecologically very diverse species. In this chapter we compile what is known about the ecology and geographical distribution of the 18 described and 5 undescribed Caenorhabditis species currently known to science. Our knowledge is still sketchy at best in most cases. Even $C$. elegans, so well known with respect to almost all other aspects of life, remains mysterious when it comes to ecology.

Of the 18 described species, 6 are dubious, which means that their descriptions are scanty and they were found only once. However, even some species which are well described or available as stocks were found only once. This could indicate that some Caenorhabditis species are very rare. Altogether, there are 13 species for which we can not make any statement on their ecology beyond listing the source of isolation.

No Caenorhabditis species is a soil nematode in the sense that populations of propagating individuals are found in soil. Soil may contain dauer juveniles, but these dauer juveniles are unlikely to develop in soil without the addition of organic matter. All Caenorhabditis species, including C. elegans, are colonizers of nutrient- and microorganism-rich organic material. It is likely that this ephemeral resource is populated rapidly, and that the local populations reach high densities, as it is observed when Caenorhabditis species are grown in the laboratory. Also, Hodgkin and Barnes (1991) demonstrated that reproductive mode and number of sperm produced by C. elegans wild type hermaphrodites is optimized for rapid population growth. In C. elegans, the induction of dauer formation is shown to be triggered by a crowding pheromone (Riddle, 1988), also suggesting that dense populations do occur under natural conditions. However, such populations are only rarely found in nature (Barrière and Félix, 2005).

Which microorganisms these nematodes feed on in nature is unknown. All Caenorhabditis species currently in culture can live more or less well on the bacterium E. coli. However, E. coli is clearly an unnatural food source. Grewal (1991) isolated 10 bacteria species which occurred together with C. elegans in mushroom compost. Only 5 of these sustained growth and reproduction of $C$. elegans for many generations in monoxenic cultures; on 4 other species nematode growth was slow and/or reproduction ceased after a few generations. On one Bacillus species, $C$. elegans could not propagate at all. Kessin et al. (1996) found that C. elegans can also feed on amoebae of the slime mold Dictyostelium discoideum.

\section{Associations with other animals}

In many Caenorhabditis species, dauer juveniles associate with other invertebrate species. There are two relevant types of such associations specified in the literature.

\subsection{Necromeny}

Dauer juveniles embark onto the associated animal and wait for their carrier to die. They then resume development and propagate on the decomposing cadaver. Typically, dauer juveniles of necromenic species do not disembark from their carriers (Schulte, 1989; Sudhaus and Schulte, 1989). 


\subsection{Phoresy}

The associated animal is being used as a means of transportation only. Dauer juveniles are carried to a new food source where they disembark from the living or dead carrier and resume development (Bovien, 1937; Richter, 1993). Typical examples are found in nematodes from carrion (e.g., C. plicata; Völk, 1950) and in the species from rotting saguaro cactus (e.g., C. drosophilae; Kiontke, 1997, 1999).

In several Caenorhabditis species intermediates between these two types of association occur: Purely phoretic species are unable to propagate on the cadaver of their carrier, while purely necromenic species never disembark. $C$. elegans, $C$. japonica and $C$. remanei leave their carrier when conditions are favorable. All three species also develop on the cadaver of the carrier at least under laboratory conditions when the carrier is sacrificed or when dead carriers are brought into the laboratory (see Section 5). We call this type of association "facultative necromeny".

\subsection{Possible adaptations to nematode-invertebrate associations}

In most necromenic and phoretic (but also in parasitic) species, dauer juveniles display a behavior which facilitates getting in contact with the associated animals. The dauer juveniles stand on the tips of their tails and sway their body. This behavior is called waving ("Winken"; Völk, 1950) or nictation (Croll and Matthews, 1977). Waving was observed in C. briggsae, C. elegans, C. japonica, C. plicata, C. remanei, C. n. sp. 1 (CB5161 et al.), C. n. sp. 2. (PS1010 et al.), and C. n. sp. 5 (JU727); dauer juveniles of $C$. drosophilae and C. n. sp. 3 (DF5070) do not wave, and waving was not observed in $C$. n. sp. 4 (SB341).

Unlike most other Secernentea, Caenorhabditis dauer juveniles shed the J2 cuticle long before they exit the dauer stage. These dauer juveniles are therefore unsheathed. Outside of Caenorhabditis unsheathed dauer juveniles are only known from phoretic species. We think that the existence of unsheathed dauer juveniles indicates an association with other animals also for those species in which such an association has not yet been observed.

Unsheathed dauer juveniles are apparently less resistant to desiccation than ensheathed dauer juveniles, which in many cases tolerate desiccation for years. Dauer juveniles of most Caenorhabditis species tolerate desiccation for only a short period of time: C. briggsae for about 3 days $\left(\right.$ at $\left.32^{\circ} \mathrm{C}\right)$, C. elegans and C. plicata for a few days at room temperature. $C$. remanei dauer juveniles were found to be still alive after a month of complete desiccation at room temperature. Dauer juveniles of $C$. n. sp. 1 tolerated desiccation for 8 months at room temperature and for 12 months at $4^{\circ} \mathrm{C}$ (W. Sudhaus unpublished).

\subsection{Vertebrate associations}

Some Caenorhabditis species have been recovered from warm blooded animals and one species from a crocodile. C. avicola was found in the intestine of a bird; C. bovis, C. clavopapillata and C. genitalis were found on mammals. The associations were described as parasitic. However, all cases but one (C. bovis) are singular findings and the association could be accidental. Even $C$. bovis does not seem to be parasitic in the strict sense of the word, but instead colonizes a bacteria-rich environment which happens to be located in the ears of zebu cattle.

\section{Ecology of Caenorhabditis species}

Available information on the ecology of well known Caenorhabditis species is summarized in Table 1. More details on these and the remaining Caenorhabditis species plus information on laboratory stocks can be found in a list under Section 5. 
Table 1. Habitat, animal associates, currently known geographical distribution and reproductive mode (gon. = gonochoristic, herm. $=$ hermaphroditic) of all Caenorhabditis species which are either well described or undescribed but in culture. Species for which there is only one record are in grey print. Species for which cultures are available are marked with an asterisk. For definition of necromenic and phoretic association see Section 2. The species are ordered according to a phylogenetic tree combined from Sudhaus and Kiontke (1996), Kiontke, Hironaka and Sudhaus (2002), Kiontke et al. (2004), and unpublished results (see also: The phylogenetic relationships of Caenorhabditis and other rhabditids).

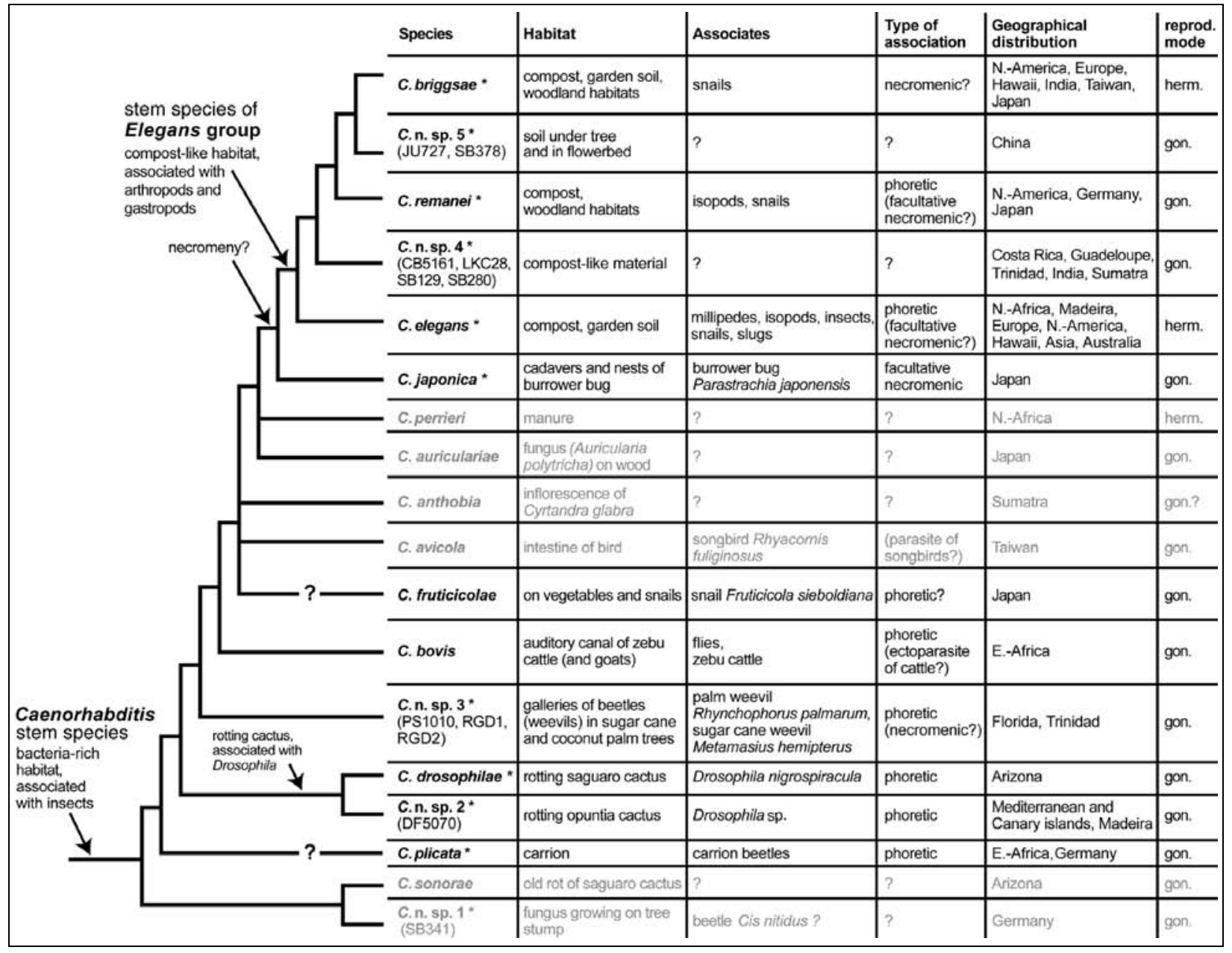

Three species of the Elegans group, C. briggsae, C. elegans and C. remanei, have very similar ecology which is discussed in comparison.

\subsection{Ecology of C. briggsae, C. elegans and C. remanei}

All three species occur in anthropogenic habitats like compost and garden soil. In these habitats, they are likely to co-occur, although so far only two of the three species were found at the same sample site: C. briggsae and C. elegans in compost in France (Barrière and Félix, 2005), C. briggsae and C. remanei in woodland in Ohio (S. Baird pers. comm.), C. remanei and C. elegans in compost in Berlin (W. Sudhaus unpublished).

C. briggsae and C. remanei were also recovered from invertebrates collected from undisturbed woodland habitat (Baird, 1999, S. Baird pers. comm.). This suggests that the natural habitat of these species is found in such woodlands, probably in decaying organic material, populated with isopods and snails. C. elegans has almost never been found outside of anthropogenic habitats despite extensive sampling (Barrière and Félix, 2005; M.-A. Félix 
pers. comm.; S. Baird pers comm.). Recently, Patrick Phillips isolated C. elegans from organic topsoil and from snails collected in State Parks in Oregon (CGC database). Its natural habitat remains largely unknown.

The only known associates of $C$. briggsae are snails. The species could be necromenic. The main associates of C. remanei seem to be isopods, but the species is also found on other arthropods and snails, and in the laboratory dauer juveniles embarked onto mites (W. Sudhaus, unpublished). For C. remanei, an exclusively necromenic way of life is unlikely. This species was found to disembark readily from living isopods (Baird, 1999) and was found as adults in compost and in sap flux (see Section 5). The picture is least clear for C. elegans. Dauer juveniles were found on a variety of different carriers: isopods, millipedes and other arthropods, snails and slugs. In the laboratory, C. elegans dauer juveniles also embarked onto large predatory mites (M.-A. Félix. pers. comm). Whether the species is necromenic or phoretic, or both is not known.

\section{Ecology of the Caenorhabditis stem species and evolution of ecological features within Caenorhabditis}

\subsection{The Caenorhabditis stem species}

A hypothesis about the habitat of the Caenorhabditis stem species can be derived from information about the habitats of the different extant Caenorhabditis species. It can be concluded that the Caenorhabditis stem species was a colonizer of nutrient-rich substrates, such as decomposing plant material. We also propose that the dauer juveniles of the Caenorhabditis stem species were phoretic. Two arguments are in favor of this view: (1) dauer juveniles of all Caenorhabditis species are unsheathed, a characteristic which is only known from nematode species phoretically associated with other animals. (2) Phoresy was shown to occur in C. bovis, C. drosophilae, C. plicata, C. sp. 2 and C. sp. 3, all of which form early branches of the Caenorhabditis tree.

In this context, it is interesting to also look into the ecology of the sister taxon of Caenorhabditis. Recent molecular studies indicate that the sister group of Caenorhabditis is a clade formed by Protorhabditis, Prodontorhabditis and Diploscapter (The phylogenetic relationships of Caenorhabditis and other rhabditids). Unfortunately, the habitat of the stem species of this clade cannot be specified. Protorhabditis species of the Xylocola group are associates of wood-boring insects. Other Protorhabditis species were found in sediments at the waterfront of inland waters ( $P$. elaphri which is associated with the carabid beetle Elaphrus riparius; and P. tristis), in the rhizosphere of plants, and in soil (Sudhaus, 1976). Most Diploscapter species are described from the rhizosphere of various plants. Prodontorhabditis species colonize beach wrack, or rotting plant material, respectively (Sudhaus, 1976).

\subsection{Evolutionary trends within Caenorhabditis}

As is obvious from table 1 and the species list in section 5, the ecology of Caenorhabditis species is very diverse. Many new habitats were colonized in the course of the evolution of these species. Some evolutionary events or trends are worth pointing out:

The stem species of $C$. drosophilae and $C$. n. sp. 2 colonized rotting cactus tissue and evolved phoresy in the ptilinal pouch on the head of cactophilic drosophilids.

Facultative necronemy could have evolved from phoresy, perhaps in the stem species of the Elegans group plus C. japonica.

Since all species of the Elegans group were found in association with snails at least occasionally, it is possible that the stem species of the Elegans group was already associated with gastropods (Sudhaus and Kiontke, 1996).

It is striking that several Caenorhabditis species were found in association with birds and mammals where they were subjected to temperatures around $37^{\circ} \mathrm{C}$. Also, C. drosophilae and C. sonorae were cultured at $31^{\circ} \mathrm{C}$. in the laboratory, and are probably exposed to peaks of considerably higher temperatures in their natural desert habitat (Kiontke, 1999). It appears that many Caenorhabditis species are surprisingly heat tolerant. This heat tolerance predisposes Caenorhabditis species to live 'pseudoparasitically' on warm-blooded animals.

We hope that the evolutionary events which led to the fascinating ecological diversity of Caenorhabditis become clearer with the discovery of new species, and with more in-depth studies of the ecology of the known species. 
Finally, a broader knowledge of the ecology of Caenorhabditis species will be essential for a more complete picture of the function of their genomes. The genomes have evolved in an ecological context after all. Therefore the function of many genes will not be unveiled under standard laboratory conditions, but only when the natural environment of the species, their specific life cycles, and their interactions with other organisms are also taken into account.

\section{List of 23 Caenorhabditis species and their ecology}

In the following, we list what is known about habitat, ecology and localities of all 23 Caenorhabditis species and one additional species which has not been characterized. Table 1 summarizes this information for 18 better known species.

\subsection{Morphologically well described species}

1. C. anthobia (Schneider, 1937) was found only once as adults in a phytotelm formed by the inflorescence of Cyrtandra glabra (Gesneriaceae) in Sumatra.

2. C. auriculariae Tsuda and Futai, 1999 was recovered once from fruiting bodies of Auricularia polytricha (Basidiomycetes) on decaying wood in Japan.

3. C. avicola Schmidt and Kuntz, 1972 was found only once as adults in the intestine of the songbird Rhyacornis fuliginosus (Muscicapidae) from Taiwan. This species could be parasitic, or the bird ingested the nematodes with its food.

4. C. bovis (Kreis, 1964) was recovered regularly over the last five decades from the inflamed outer auditory canals of zebu cattle (Bos primigenius f. (taurus) indicus) with otitis, and once of goats. All records are from Eastern Africa, ranging from Sudan to South Africa. Most records are from Tanzania (type locality; Msolla et al., 1993). C. bovis was rarely found in manure-containing soil, and also on flies (Muscoidea). Apparently, dauer juveniles of this species are transmitted by unidentified flies which visit the infected ears of zebu cattle (Msolla et al., 1989). A candidate for this fly associate of C. bovis is Chrysomya bezziana, the larvae of which were found in inflamed zebu auditory canals (Msolla et al., 1993). C. bovis is often found together with Rhabditis blumi, another rhabditid species which colonizes inflamed ears of zebu (Msolla et al., 1989).

The natural habitat of $C$. bovis, apart from domesticated animals, is unknown.

C. bovis tolerates quite high temperatures. In the laboratory it was grown at $32-35^{\circ} \mathrm{C}$ (Kassuku et al., 1989). The temperature in zebu cattle ears, where the species propagates in nature, is probably above $37^{\circ} \mathrm{C}$ since the tympanic temperature of cattle was measured as $38^{\circ} \mathrm{C}$ and above (Hahn, 1999).

5. C. briggsae (Dougherty and Nigon, 1949) is found in rich garden soil and in compost heaps (type locality California: Briggs Gochnauer and McCoy, 1954; India: Fodor et al., 1983; France: M.-A. Félix pers. comm., Iceland: A. Barrière pers. comm.). It was also found in association with snails: with Oncomelania hupensis in Taiwan and Japan (Sudhaus and Kiontke, 1996), once with Oxychilus alliarius in Dayton, Ohio (S. Baird pers. comm.), and with Oxychilus sp. and Helix aspersa in France (M.-A. Félix pers. comm.).

Apart from the record on Oxychilus alliarius in Ohio, which was collected from a natural woodland habitat, all records are from anthropogenic habitats. Consequently, the natural habitat of this species is unknown.

C. briggsae may be synonymous with C. clavopapillata.

The Caenorhabditis Genetics Center (CGC) keeps eight wild isolates of $C$. briggsae:

AF16: soil in Ahmedabad, India. (= G16, Fodor et al., 1983)

HK104: Okayama, Japan

HK105: Sendai, Japan

PB800: from soil at the base of mushrooms, Dayton Ohio

PB826: from unidentified snail in Hueston Woods State Park, Ohio 
JU725: from mushroom compost in a farmyard $1 \mathrm{~km}$ south of Yangshuo, Guangxi, China

JU726: from soil with freshly added compost in a cabbage field in Chengyang Village, $20 \mathrm{~km}$ north of Sanjiang, Guangxi, China

VT847: Hawaii

6. C. drosophilae (Kiontke, 1997) is found regularly in fresh rotting saguaro cactus tissue in Arizona, USA. Dauer juveniles are phoretic on Drosophila nigrospiracula (Diptera, Drosophilidae). They are carried on the head of the fly inside a pouch which is formed by the retracted ptilinum (an inflatable sack which brachyceran flies use to break open the pupal case). The dauer juveniles receive a cue from the fly without which they never exit from the dauer stage, even when experimentally placed on fresh rotting cactus tissue. Thus, in this species phoresy is physiologically necessary to resume development (Kiontke, 1997). Dauer juveniles do not actively disembark from their carriers. It is likely that they are released after the fly had died on rotting saguaro cactus (Kiontke, 1999).

The NYU rhabditid collection currently keeps one strain of C. drosophilae:

DF5077 from rotting saguaro cactus, Tucson, Arizona, USA.

7. C. elegans (Maupas, 1899) (syn. Rhabditis kowalewskyi Golovin, 1901) is mostly found in anthropogenic habitats: in compost, mushroom beds, and garden soil in Europe, Madeira, North Africa (type locality: Algeria), Asia (Kazan, Volga region), North America, Hawaii and Australia. There are also rare records of $C$. elegans from the waterfront of saprobic rivers in Germany (Hirschmann, 1952), and from fresh water habitats in Italy (Zullini, 1982). The species was also found once in the frass of the European silver fir weevil (Pissodes piceae) in Germany (Rühm, 1956).

C. elegans dauer juveniles were found on isopods (Oniscus asellus in France: Barrière and Félix, 2005; and Porcellio scaber bought from Ward's Biological Supply and from Connecticut Valley Biological Supply: S. Baird pers. comm.), occasionally on moth flies (Psychoda, Diptera, from sewage in Germany: Sudhaus and Kühne, 1989), on snails (Helix sp., Oxychilus sp., Pomatias elegans in France, Barrière and Félix, 2005; Helix aspersa in California USA, Caswell-Chen et al., 2005) and slugs (Limax tenellus in Germany: Mengert, 1953), on mites in England (Staniland, 1957), and on millipedes (Ommatoiulus moreletii in Australia: Sudhaus and Kiontke, 1996, and Glomeris in France: Barrière and Félix, 2005).

Population genetic studies (Koch et al., 2000, Sivarsundar and Hey, 2003, Barrière and Félix, 2005, Haber et al., 2005) suggest that $C$. elegans migrates over surprisingly large distances. This could be facilitated by their carriers in case of dispersal within the range of these organisms. However, the same C. elegans variants with respect to microsatellites (Sivarsundar and Hey, 2003, Haber et al., 2005), AFLP (Barrière and Félix, 2005), single nucleotide polymorphisms (Koch et al., 2000), transposons (Egilmez et al., 1995), mitochondrial DNA sequences (Denver et al., 2003), and behavioral, physiological and morphological characteristics (Hodgkin and Doniach, 1997, De Bono and Bargman, 1998) are found in both North America and Europe. This suggests that the species migrates between continents. Given the anthropogenic habitat of C. elegans it is conceivable that this species is distributed by human activities.

The only study which rigorously tested in which developmental stage C. elegans is present in samples upon collection (Barrière and Félix, 2005) finds that even in rich compost soil C. elegans is mostly present as dauer juveniles. Other stages were discovered only rarely, always on the uppermost layer of the compost which contained freshly rotting organic material. In accord with this preference for bacteria-rich substrates, C. elegans prefers rather low oxygen concentrations of $6 \%$ and avoids not only very low oxygen concentrations $(<2 \%)$ but also higher oxygen concentrations (>12\%) (Gray et al., 2004).

The natural habitat of $C$. elegans remains unknown.

The CGC keeps to date 65 wild isolates of $C$. elegans:

AB1, AB2: decaying vegetable matter on garden soil, Adelaide Australia

$\mathrm{AB} 3, \mathrm{AB} 4$ : soil in plant nursery plot, Adelaide, Australia

CB3191-97: garden in Altadena, CA 


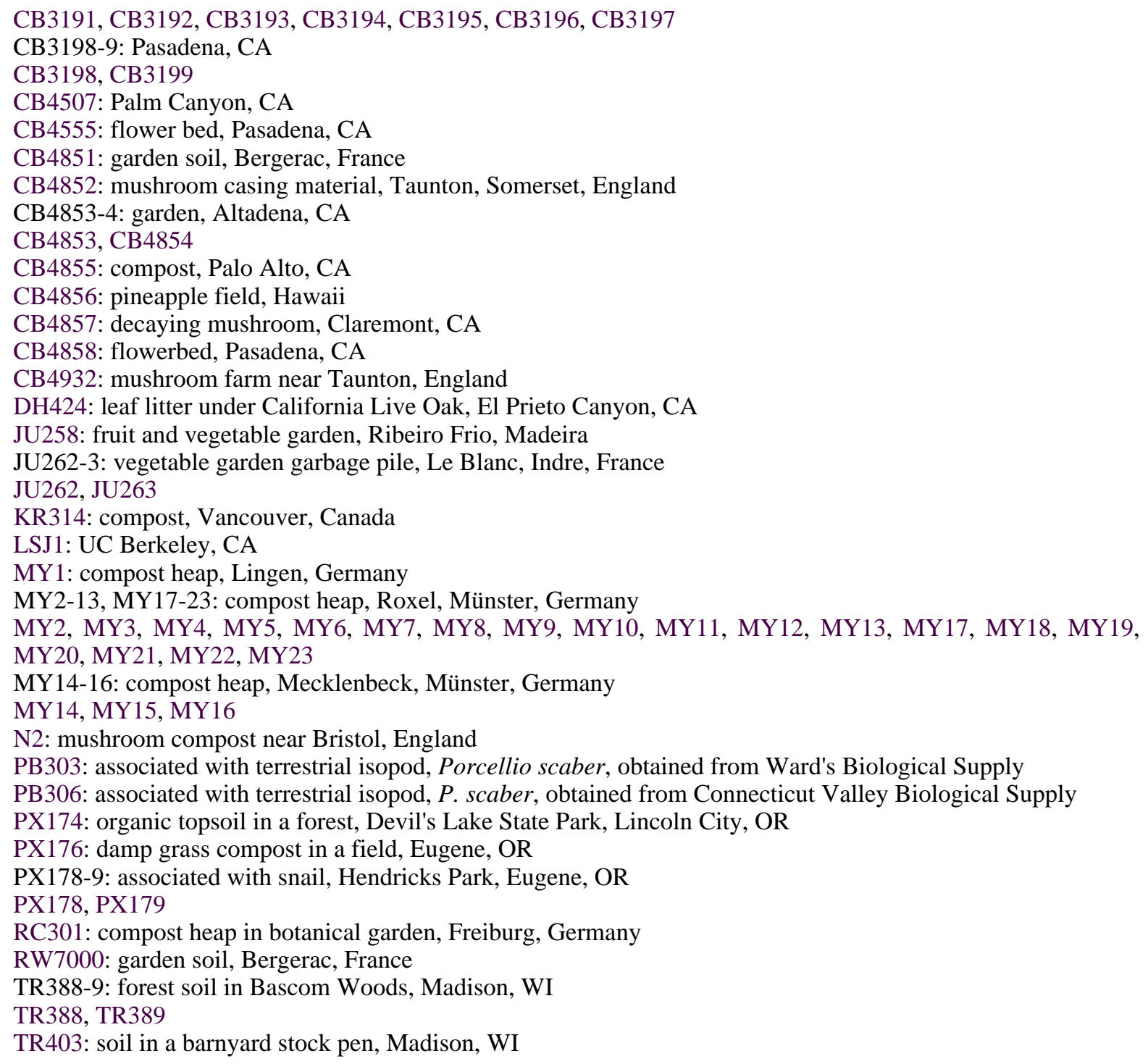

8. C. japonica Kiontke, Hironaka and Sudhaus, 2002 was recovered as dauer juveniles from adult shield bugs Parastrachia japonensis (Heteroptera, Cydnidae) from the Japanese islands Kyushu and Shikoku. The dauer juveniles are found under the scutellum of the bugs (Kiontke et al., 2002).

The ecology of this species is currently under investigation (T. Yoshiga, pers. comm.) and not yet fully understood. $P$. japonensis females raise their offspring in nests which they provision with food, drupes of the tree Schoepfia jasminodera. C. japonica was found to propagate in these nests, probably on dead eggs, nymphs and exuviae of the bugs. However, reproducing $C$. japonica were also found on the cadavers of adult bugs. Consequently, this species is facultative necromenic. In the nest, $C$. japonica dauer juveniles embark on second stage nymphs and transfers to the next stage of their carrier during its molt. Initially, bugs of both sexes carry dauer juveniles. However, during the period of reproductive diapause of $P$. japonensis (from July till May of the following year), the number of $C$. japonica dauer juveniles increases on female bugs and decreases on males. It is unknown whether dauer juveniles transfer from male to female carriers (T. Yoshiga, pers. comm.). There is evidence that most $C$. japonica juveniles enter the dauer stage regardless of food availability or population density. (K. Kiontke and T. Yoshiga, unpublished observation). 
The NYU rhabditid collection maintains currently two wild isolates of $C$. japonica:

DF5079: from Parastrachia japonensis, Hinokuma, Saga, Japan

DF5080: from P. japonensis, Takeo, Saga, Japan

9. C. perrieri (Maupas, 1900) was found only once in soil containing manure in North Africa

10. C. plicata (Völk, 1950) is a rare species which was found on carrion in Germany (type locality) and East Africa (Sudhaus, 1974). C. plicata dauer juveniles are phoretic on various carrion visiting beetles, like Necrodes, Nicrophorus (Silphidae) and Hister (Histeridae). It is likely that the nematodes hibernate as dauer juveniles on their carriers.

The NYU rhabditid collection maintains one strain of C. plicata.

SB355: from carrion beetle on dead marten, Berlin, Germany.

11. C. remanei (Sudhaus, 1974) (syn. C. vulgaris Baird et al., 1994) is regularly found in fresh compost in Germany (type locality) and North America, and was once found in association with the snail Fruticicola sieboldiana on Kyushu, Japan. The species was also found in a pile of bird pellets and in decomposing wood populated with isopods and millipedes. One population was observed in slime discharged by the stump of a maple tree which was recently cut down (all in Germany: W. Sudhaus unpublished).

Dauer juveniles were found associated with isopods (up to 60\% of Armadillidium vulgare from compost in Berlin, Germany: A. Weber and W. Sudhaus unpublished; Cylisticus convexus, Armadillidium nasutum, Porcellio scaber, Trachelipus rathkii from woodland habitats in Ohio: Baird, 1999), with snails (Oxychilus spp.: Baird et al., 1994, Fruticicola sieboldiana: W. Sudhaus, unpubl.), once with a slug (Arion sp.) in Germany (Sudhaus, 1974), once with 'firefly larvae' (Lampyridae?) in Ohio (S. Baird pers. comm.), and once with a staphylinid beetle in Berlin (W. Sudhaus unpubl.). Adult C. remanei were found on pieces of apple which were placed on the surface of a compost heap in Berlin. C. remanei was the first species in a succession of nematode colonizers of this substrate. It is likely that the isopods transported the nematodes to this substrate, since isopods carrying C. remanei dauer juveniles were collected from the same site (C. Wedler and W. Sudhaus unpubl.).

The type of association of $C$. remanei with isopods is probably phoresy, since in experiments waving dauer juveniles which had embarked on isopods disembarked quickly when their carriers were kept in a sufficiently damp environment (Baird, 1999). However, in the laboratory C. remanei also propagates on the cadavers of sacrificed isopods. Therefore C. remanei was described as being necromenic by Baird et al. (1994).

The natural habitat of $C$. remanei is unknown. The species was found on several isopod species collected in undisturbed woodland habitats in Ohio. This indicates that $C$. remanei does occur in natural woods (Baird, 1999). But where this species propagates is not known.

The CGC currently maintains 10 wild isolates of $C$. remanei:

EM464: garden, Brooklyn, NY

PB206, 212, 219, 227: associated with terrestrial isopod, Trachelipus rathkii, Wright State University Biology Preserve, Dayton Ohio

PB206, PB212, PB219, PB227

PB228: associated with terrestrial isopod, Armadillidium vulgare, Eastwood MetroPark, Dayton Ohio

PB229: associated with terrestrial isopod, Cylisticus convexus, Englewood MetroPark, Dayton Ohio

JU724: from soil in cultivated fields (beans, cereal) in Zhouzhuang, Jiangsu, China

SB146: compost, Freiburg, Germany

VT733: soil, Connecticut

12. C. sonorae (Kiontke, 1997) was found only once in old saguaro cactus rot in Arizona. 


\subsection{Well known undescribed species}

13. Caenorhabditis n. sp. 1 (SB341) found once in galleries inside of the fungus Ganoderma applanatum (Polyporaceae) which grew on the stump of a tree a few centimeters above ground in Berlin, Germany. These galleries were frequented by beetles of the species Cis nitidus. It is uncertain whether $C$. n. sp. 1 is associated with these beetles.

The NYU rhabditid collection currently keeps the strain SB341 of $C$. n. sp. 1.

14. Caenorhabditis n. sp. 2 (DF5070) was found in rotting Opuntia cactus tissue on Mediterranean islands (Mallorca, Sardinia), on Madeira and on the Canary Islands. The ecology of this species is likely to be similar to that of its sister species $C$. drosophilae. Dauer juveniles are transported in the ptilinal pouch on the head of Drosophila sp. (probably D. buzzatii).

Caenorhabditis n. sp. 2 is a neozoic species introduced to the Old World in historical times, either with its host plant from Mexico or with the cactophilic Drosophila buzzatii from South America (Fontdevila et al., 1982).

The NYU rhabditid collection currently keeps strain DF5070 of C. n. sp. 2 from rotting opuntia from Sardinia, Italy.

15. Caenorhabditis n. sp. 3 (PS1010, RGD1, RGD2) is associated with palm and sugarcane weevils, Rhynchophorus palmarum and Metamasius hemipterus (Curculionidae) in Trinidad and Florida. The nematodes propagate on decomposing tissue of coconut palms and sugar cane in the galleries of the weevils (R. Giblin-Davis, pers. comm.). Dauer larvae wave and are transported by adult weevils. The association is probably phoretic, although $C$. n. sp. 3 can develop on dead weevils.

The CGC currently keeps 3 wild isolates of $C$. n. sp. 3 .

PS1010 from Metamasius hemipterus, Dade County, FL

RGD1-2 from Metamasius hemipterus, Fort Lauderdale, FL

RGD1, RGD2

16. Caenorhabditis n. sp. 4 (CB5161, LKC28, SB129, SB280) was found in decaying, compost-like plant material in Sumatra, India, Trinidad, Costa Rica, and Guadeloupe. Thus, this species may have a circumtropical distribution between the equator and the Tropic of Cancer. Dauer juveniles show waving behavior which indicates that they are phoretic or necromenic. The carriers are unknown.

The CGC currently keeps 4 wild isolates of $C$. n. sp. 4 .

CB5161: sugar cane, Trinidad

LKC28: plant roots in nursery, Costa Rica

SB129: compost-like material, Bohorok, Sumatra

SB280: rotting banana leaves, Guadeloupe

17. Caenorhabditis n. sp. 5 (JU727, SB378) was found once in soil under a tree in Chengyang, $20 \mathrm{~km}$ North of Sanjiang, Guangxi, China and once in soil from a flowerbed in a park in Guagzhou, Guangdon, China. Dauer juveniles show waving behavior indicating an association with other animals.

The CGC keeps currently strain JU727 of C. n. sp. 5.

\subsection{Dubious species}

The following species were found only once, and their descriptions are scanty. It is possible that some of them are synonymous with other species.

18. C. clavopapillata (Kreis and Faust, 1933) was found once on several laboratory animals kept in the Parasitology Laboratory at Tulane University (New Orleans, Louisiana, USA). The nematodes were found in feces of dogs, also in the fecally contaminated fur of dogs, of a rhesus monkey (Macaca mulatta), and of a 
"capuchin from Panama" (cf. Cebus capucinus). The species is dubious; it may be synonymous with $C$. briggsae. Reproductive mode unknown.

19. C. craspedocerca (Völk, 1950): There is only one record of this species from the earthworm Eisenia rosea (Lumbricidae) in Germany. The association with this earthworm could be accidental since $C$. craspedocerca appeared only once in the extensive study of earthworm nematodes by Völk (1950) and was never found again. Also, different from true earthworm nematodes, $C$. craspedocerca could be cultivated on potato. $C$. craspedocerca may be synonymous with $C$. perrieri. Hermaphroditic.

20. C. formosana (Yokoo and Okabe, 1968) was found once associated with the amphibious snail Oncomelania hupensis in Taiwan. Gonochoristic.

21. C. fruticicolae (Shinohara, 1960): With regard to its morphology and sound phylogenetic position, this species is dubious, but its ecology is comparatively well described. It was found at one time in 3 locations in Japan in the intestine of the snail Fruticicola sieboldiana and on vegetable plants on which the snail was present. More than $60 \%$ of 115 investigated snails carried these nematodes. In experiments, snails ingested C. fruticicolae dauer juveniles orally and emitted some of them alive upon defecation. Dauer juveniles tolerate $37^{\circ} \mathrm{C}$ for at least 3 days. Gonochoristic.

22. C. genitalis (Scheiber, 1880) was once isolated from the external genitalia of an ill woman in Europe. Gonochoristic.

23. C. oncomelaniae (Yokoo and Okabe, 1968) was found only once associated with the amphibious snail Oncomelania hupensis in Japan. Gonochoristic.

\subsection{Unidentified species}

24. Caenorhabditis sp.: An unidentified hermaphroditic species from the Elegans group was found as adults in the liver of an African crocodile (Osteolaemus tetraspis) which had died in the Port Elizabeth Zoological Garden in South Africa (F. Huchzermeyer and W. Sudhaus unpubl.).

\section{Acknowledgements}

We are grateful to Scott Baird, Antoine Barrière, Marie-Anne Félix, and Toyoshi Yoshiga for sharing their unpublished results. We also thank Scott Baird, Marie-Anne Félix, David H. A. Fitch and Erich M. Schwarz for helpful comments on the manuscript.

\section{References}

Baird, S.E. (1999). Natural and experimental association of Caenorhabditis remanei with Trachelipus rathkii and other terrestrial isopods. Nematology 1, 471-475. Article

Baird, S.E., Fitch, D.H.A., and Emmons, S.W. (1994). Caenorhabditis vulgaris sp.n. (Nematoda: Rhabditidae): a necromenic associate of pill bugs and snails. Nematologica 40, 1-11.

Barrière, A., and Félix, M.-A. (2005). High local genetic diversity and low outcrossing rate in Caenorhabditis elegans natural populations. Current Biology 15, 1176-1184.

Bovien, P. (1937). Some types of association between nematodes and insects. Videnskabelige Meddelelser fra Dansk Naturhistorik Forening 101, 1-114.

Briggs Gochnauer, M., and McCoy, E. (1954). Responses of a soil nematode, Rhabditis briggsae, to antibiotics. J. Exptl. Zool. 125, 377-406. Article 
Caswell-Chen, E.P., Chen, J., Lewis, E.E., Douhan, G.W., Nadler, S.A., and Carey, J.R. (2005). Revising the standard wisdom of C. elegans natural history: ecology of longevity. Sci. Aging Knowl. Environ. 40, pe30. Abstract Article

Croll, N.A., and Matthews, B.E. (1977). Biology of Nematodes. Glasgow and London: Blackie and Son.

De Bono, M., and Bargmann, C.I. (1998). Natural variation in a neuropeptide Y receptor homolog modifies social behavior and food response in C. elegans. Cell 94, 679-689. Abstract Article

Denver, D.R., Morris, K., and Thomas, W.K. (2003). Phylogenetics in Caenorhabditis elegans: an analysis of divergence and outcrossing. Mol. Biol. Evol. 20, 393-400. Abstract Article

Dougherty, E.C., and Nigon, V. (1949). A new species of the free-living nematode genus Rhabditis of interest in comparative physiology and genetics. J. Parasit. 35 (suppl.), 11.

Egilmez, N.K., Ebert, R.H.A., and Shmookler Reis, R.J. (1995). Strain evolution in Caenorhabditis elegans: transposable elements as markers of interstrain evolutionary history. J. Mol. Evol. 40, 372-381. Abstract Article

Fodor, A., Riddle, D.L., Nelson, F.K., and Golden, J.W. (1983). Comparison of a new wild-type Caenorhabditis briggsae with laboratory strains of C. briggsae and C. elegans. Nematologica 29, 203-217.

Fontdevila, A., Ruiz, A., Ocana, J., and Alonso, G. (1982). Evolutionary history of Drosophila buzzatii. II. How much has chromosomal polymorphism changed in colonization? Evolution 36, 843-851.

Golovin, E. (1901). Observations on nematodes. I. Phagocytic organs. (Russ.). Uchen. Zapiski Imp. Kazan. Univ. $68,1-50$.

Gray, J.M., Karow, D.S., Lu, H., Chang, A.J., Chang, J.S., Ellis, R.E., Marletta, M.A., and Bargmann, C.I. (2004). Oxygen sensation and social feeding mediated by a C. elegans guanylate cyclase homologue. Nature 430, 317-322. Abstract Article

Grewal, P.S. (1991). Influence of bacteria and temperature on the reproduction of Caenorhabditis elegans (Nematoda: Rhabditidae) infesting mushrooms (Agaricus bisporus). Nematologica 37, 72-82.

Haber M., Schungel M., Putz A., Muller S., Hasert B., and Schulenburg H. (2005). Evolutionary history of Caenorhabditis elegans inferred from microsatellites: evidence for spatial and temporal genetic differentiation and the occurrence of outbreeding. Mol. Biol. Evol. 22, 160-173. Abstract Article

Hahn G.L. (1999). Dynamic responses of cattle to thermal heat loads. J. Anim. Sci. 77, 10-20. Abstract

Hirschmann, H. (1952). Die Nematoden der Wassergrenze mittelfränkischer Gewässer. Zool. Jb. Syst. 81, 313-407.

Hodgkin, J.A., and Barnes, T.M. (1991). More is not better: brood size and population growth in a self-fertilizing nematode. Proc. R. Soc. Lond. B. 246, 19-24. Abstract

Hodgkin, J.A., and Doniach, T. (1997). Natural variation and copulatory plug formation in Caenorhabditis elegans. Genetics 146, 149-164. Abstract

Kassuku, A.A., Mawere, M.S., and Msalilwa, I.P. (1989). Laboratory cultivation of Rhabditis bovis on different culture media. Tanz. Vet. Bull. 9, 34-37.

Kessin, R.H., Gundersen, G.G., Zaydfudim, V., and Grimson, M. (1996). How cellular slime molds evade nematodes. PNAS 93, 4857-4861. Abstract Article

Kiontke, K. (1997). Description of Rhabditis (Caenorhabditis) drosophilae n. sp. and R. (C.) sonorae n. sp. (Nematoda: Rhabditida) from saguaro cactus rot in Arizona. Fundam. appl. Nematol. 20, 305-315.

Kiontke, K. (1999). The Nematode Fauna of Rotting Cactus and Phasmids in Male Secernentea. Berlin: Dissertation.de. 
Kiontke, K., Hironaka, M., and Sudhaus, W. (2002). Description of Caenorhabditis japonica n. sp. (Nematoda: Rhabditida) associated with the burrower bug Parastrachia japonensis (Heteroptera: Cydnidae) in Japan. Nematology 4, 933-941. Article

Kiontke, K., Gavin, N.P., Raynes, Y., Roehrig, C., Piano, F., and Fitch, D.H.A. (2004). Caenorhabditis phylogeny predicts convergence of hermaphroditism and extensive intron loss. Proc. Natl. Acad. Sci. U.S. 101, 9003-9008. Abstract Article

Koch, R., van Luenen, H.G.A.M., van der Horst, M., Thijssen, K.L., and Plasterk, R.H.A. (2000). Single nucleotide polymorphisms in wild isolates of Caenorhabditis elegans. Genome. Res. 10, 1690-1696. Abstract Article

Kreis, H.A. (1964). Ein neuer Nematode aus dem äußeren Gehörgang von Zeburindern in Ostafrika, Rhabditis bovis n. sp. (Rhabditoidea, Rhabditidae). Schweiz. Arch. Tierheilk. 106, 372-378.

Kreis, H.A., and Faust, E.C. (1933). Two new species of Rhabditis (Rhabditis macrocerca and R. clavopapillata) associated with dogs and monkeys in experimental Strongyloides studies. Trans. Am. Micr. Soc. 52, 162-172.

Maupas, E. (1899). La mue e l'enkystement chez les nématodes. Arch. Zool. expér. et gén. 7, 563-628.

Maupas, E. (1900): Modes et formes de reproduction des nématodes. Arch. Zool. expér. et gén. 8, 463-624.

Mengert, H. (1953). Nematoden und Schnecken. Z. Morph. u. Ökol. Tiere 41, 311-349. Article

Msolla, P., Kimera, I.S., Kassuku, A.A., Semuguruka, W.D., and Shoo, M.K. (1989). The role of flies, manure and soil in the epidemiology of bovine parasitic otitis. Proc. 7th Tanzania Vet. Assoc. Sci. Conf. 7, 101-109.

Msolla P., Semuguruka, W.D., Kassuku, A.A., and Shoo, M.K. (1993). Clinical observations of bovine parasitic otitis in Tanzania. Trop. Anim. Health Prod. 25, 15-18. Article

Richter, S. (1993). Phoretic association between the dauerjuveniles of Rhabditis stammeri (Rhabditidae) and life history stages of the burying beetle Nicrophorus vespilloides (Coleoptera: Silphidae). Nematologica 39, 346-355.

Riddle, D.L. (1988). The Dauer Larva. In: The Nematode Caenorhabditis elegans. W.B. Wood, ed., Cold Spring Harbor: Cold Spring Harbor Laboratory, pp. 393-412.

Rühm, W. (1956). Die Nematoden der Ipiden. Parasitol. Schriftenr. 6, 1-437.

Scheiber, S.H. (1880). Ein Fall von mikroskopisch kleinen Rundwürmern - Rhabditis genitalis - im Urin einer Kranken. Arch. patholog. Anatomie Physiol. klin. Med. 82, 161-175. Article

Schmidt, G., and Kuntz, R.E. (1972). Caenorhabditis avicola sp. n. (Rhabditidae) found in a bird from Taiwan. Proc. Helminthol. Soc. Wash. 39, 189-191.

Schneider, W. (1937). Freilebende Nematoden der Deutschen Limnologischen Sundaexpedition nach Sumatra, Java und Bali. Arch. Hydrobiol., 15 (Suppl.), 30-108.

Schulte, F. (1989). The association between Rhabditis necromena Sudhaus and Schulte, 1989 (Nematoda: Rhabditidae) and native and introduced millipedes in South Australia. Nematologica 35, 82-89.

Shinohara, T. (1960). Studies on Rhabditis (Nematoda, Rhabditidae) (Japan.). J. Kurume Med. Assoc. 23, 2777-2819.

Sivarsundar, A., and Hey, J. (2003) Population genetics of Caenorhabditis elegans: the paradox of low polymorphism in a widespread species. Genetics $163,147-157$. Abstract

Staniland, L.N. (1957). The swarming of rhabditid eelworms in mushroom houses. Plant Pathol. 6, 61-62.

Sudhaus, W. (1974). Zur Systematik, Verbreitung, Ökologie und Biologie neuer und wenig bekannter Rhabditiden (Nematoda). 2. Teil. Zool. Jb. Syst. 101, 417-465. 
Sudhaus, W. (1976). Vergleichende Untersuchungen zur Phylogenie, Systematik, Ökologie, Biologie und Ethologie der Rhabditidae (Nematoda). Zoologica (Stuttgart) 43, 1-229.

Sudhaus, W., and Kiontke, K. (1996). Phylogeny of Rhabditis subgenus Caenorhabditis (Rhabditidae, Nematoda). J. Zool. Syst. Evol. Res. 34, 217-233.

Sudhaus, W., and Kühne, R. (1989). Nematodes associated with Psychodidae: description of Rhabditis berolina sp. n. and redescription of $R$. dubia Bovien, 1937 (Nematoda: Rhabditidae), with biological and ecological notes, and a phylogenetic discussion. Nematologica 35, 305-320.

Sudhaus, W., and Schulte, F. (1989). Rhabditis (Rhabditis) necromena sp. n. (Nematoda: Rhabditidae) from South Australian diplopoda with notes on its sibling $R$. myriophila Poinar, 1986 and $R$. caulleryi Maupas, 1919. Nematologica 35, 15-24.

Tsuda, K., and Futai, K. (1999). Description of Caenorhabditis auriculariae n. sp. (Nematoda: Rhabditida) from fruiting bodies of Auricularia polytricha. Jpn. J. Nematol. 29, 18-23.

Völk, J. (1950). Die Nematoden der Regenwürmer und aasbesuchenden Käfer. Zool. Jb. Syst. 79, 1-70.

Yokoo, T., and Okabe, K. (1968). Two new species of genus Rhabditis (Nematoda: Rhabditidae) found in the intermediate host of Schistosoma japonica, Oncomelania hupensis nosophora and Oncomelania hupensis formosana. Agric. Bull. Saga Uni. 25, 69-78.

Zullini, A. (1982). Nematodi (Nematoda). In: Guide per il riconoscimento delle specie animali delle acque interne Italiane. Vol. 17. (Verona: Consiglio Nazionale delle Ricerche).

All WormBook content, except where otherwise noted, is licensed under a Creative Commons Attribution License 